\title{
Examining the Interaction of Acceptance and Understanding: How Does the Relationship Change with a Focus on Macroevolution?
}

\author{
Louis S. Nadelson • Sherry A. Southerland
}

Published online: 19 January 2010

(C) Springer Science+Business Media, LLC 2010

\begin{abstract}
The goal of this research was to illuminate the relationship between students' acceptance and understanding of macroevolution. Our research questions were: (1) Is there a relationship between knowledge of macroevolution and acceptance of the theory of evolution?; (2) Is there a relationship between the amount of college level biology course work and acceptance of evolutionary theory and knowledge of macroevolution?; and (3) Can college student acceptance of the theory of evolution and knowledge of macroevolution change over the course of a semester? The research participants included 667 students from a firstsemester biology course and 74 students from the evolutionary biology course. Data were collected using both the MATE (a measure of the acceptance of evolutionary theory) and the MUM (a measure of understanding of macroevolution). Pre-instruction data were obtained for the introductory biology course, and pre- and post-data were obtained for the evolutionary biology course. Analysis revealed acceptance of evolution (as measured by the MATE) was correlated to understanding of macroevolution, and the number of biology courses was significantly correlated to acceptance and knowledge of macroevolution. Finally, there was a statistically significant change in students' understanding of macroevolution and acceptance of evolution after the one-semester evolutionary biology course. Significance of these findings is discussed.
\end{abstract}

L. S. Nadelson $(\triangle)$

College of Education, Boise State University,

1910 University Drive,

Boise, ID 83725-1700, USA

e-mail: LouisNadelson@BoiseState.edu

S. A. Southerland

School of Teacher Education, Florida State University,

205 Stone Building,

Tallahassee, FL 32306-4495, USA
Keywords Acceptance $\cdot$ Understanding $\cdot$ Macroevolution

\section{Introduction}

There is a growing interest in more deeply investigating the role affective constructs play in shaping students' learning (Sinatra and Pintrich 2002). Educational researchers are beginning to understand more fully what classroom teachers have long recognized; multiple variables combine to influence learning, and so learning is seldom a straightforward, rational, or linear process (Sinatra et al. 2008). Some scholars examine the role learners' epistemological beliefs play in shaping learning (Wood and Kardash 2002), others focus on the actions of learning dispositions (Stanovich and West 1997) or motivation (Elliot and Dweck 2005). When instructional content focuses on controversial issues, such as biological evolution, the affective construct that surfaces most quickly is belief. In these situations, beliefs are commonly thought to shape students' learning of science concepts. This interplay between belief and knowledge is the focus of our research. Belief and knowledge in science are paradoxical because they are arguably distinctly different concepts (Smith 1994) and yet, inextricably related (Smith and Siegel 2004). The goal of our research is to further illuminate the relationship between students' acceptance of evolution and their understanding of this construct-and we do this in the relatively unexplored conceptual field of macroevolution.

Knowledge and Belief

However, before proceeding, it is necessary to set some guideposts for our work. The first standard we intend to establish is the distinction between knowledge and belief. 
There has been on-going debate regarding the similarity and differences between knowledge and belief in science education (Smith 1994; Smith and Siegel 2004; Southerland et al. 2001). Organizations such as the Gallup poll may further contribute to the conflation of knowledge and belief, as they conduct and report on the response to their evolution survey query regarding the "belief about the origin of human beings" (Newport 2008). This approach to assessing public opinion about human evolution can easily be perceived to muddle acceptance and understanding. Some argue there are significant differences between knowledge and belief and these differences should be emphasized (Smith and Siegel 2004), while others contend that emphasizing the distinction between the two constructs may negatively impact opportunities for student learning (Cobern 2004).

Regardless of the pedagogical and philosophical positions in science education regarding attention toward knowledge and belief, there is general agreement these are two distinctly unique constructs. Alexander and Dochy (1995) and Smith and Siegel (2004) contend that the fundamental difference between knowledge and belief is that knowledge is based on an evaluation of evidence and is subject to revision based on empirical examination, while belief is based on faith and does not stem from or require empirical proof. From an educational perspective, it is useful to associate knowledge with understanding, while belief may be associated with acceptance of the validity of a construct (Southerland et al. 2001). Because of the attention that knowledge and belief have received in evolution education research and continue to experience, there is justification for establishing this guidepost.

\section{Belief and Acceptance}

Many researchers in evolution education are careful to draw a distinction between a learners' belief in a construct and their acceptance of that construct (Nadelson 2009; National Academy of Sciences 1998: Sinatra et al. 2003; Smith et al. 1995; Southerland 2000). Smith (1994) argues that belief of a construct implies that the judgment of the validity of knowledge is based on personal convictions, opinions, and the degree of congruence with other belief systems. In contrast, acceptance of the validity of knowledge is based on an examination of the plausibility, persuasiveness, and fruitfulness of the empirical support for the construct. For example, a learner might not believe that mosquitoes are a beneficial organism, but may accept, according to scientific evidence, that all organisms have a function within ecosystems and biomes. Unlike belief, for a learner to accept a theory is valid is not dependent on personal perspectives of the supernatural, nature, and the world, but rather a rational evaluation of that knowledge claim (Rutledge and Mitchell 2002; Smith 1994). We maintain acceptance, as a construct, relies on recognizing the validity of a scientific knowledge based on supporting evidence and is not simply a matter of personal opinion, which places acceptance in strong contrast with belief (Southerland et al. 2001).

\section{Acceptance and Knowledge of Evolution}

How does a learner's understanding of evolution intersect with their acceptance of the theory? It stands to reason that the stability of individuals' acceptance of evolution-related concepts, hypotheses, and the theory as a whole, may be directly related to their levels of familiarity and understanding of the associated evidence. However, research suggests that affective factors may serve as a barrier to the development of knowledge of evolution, which in turn could constrain acceptance of the theory (Brem et al. 2003; Smith 1994). That is, students may reject evolution theory due to negative affective beliefs that evolution is in conflict with their personal beliefs (Dagher and BouJaoude 1997; Southerland 2000 ), or they may simply view the prospect of evolution as disheartening (Brem et al. 2003), reducing their willingness to engage in learning more about the theory. When students hold such perspectives and "tune out" to evolution-related instruction, they are more likely to continue to reject the scientific view. This perspective suggests that students' affective stance toward evolution must be addressed prior to or concurrently with instruction to have success (Cobern 2004; Jackson 2000; Meadows et al. 2000; Scharmann 1990; Smith 1994; Smith and Siegel 2004).

An alternative view suggests that students' knowledge serves as the barrier to developing an acceptance of scientific explanations of phenomena, including biological evolution (Lawson and Worsnop 1992; Lawson et al. 2000). According to this position, students cannot evaluate the strength of a theory until they have sufficient conceptual knowledge upon which to base their judgments. There are important pedagogical ramifications if both these assertions are true. If correct, changing students' understanding of evolution would necessitate addressing their affective perspectives before they can learn about evolution topics. But, ironically, students are not likely to change their views of a theory until they have sufficient knowledge to do so. The probable interplay between these two viewpoints makes the difficulties and complexity of teaching and learning about evolution all the more apparent.

The results of empirical research on the effect of knowledge on belief or acceptance have been mixed but largely negative (Nehm and Schonfeld 2007). A number of studies suggest that knowledge-oriented interventions do not change students' beliefs or acceptance (Angiullo et al. 1996; Carmel et al. 1992; Erickson et al. 2003; Harris et al. 1991; Koumi and Tsiantis 2001; Showers and Shrigley 1995). Indeed, there is evidence to suggest that content 
instruction in evolutionary biology does not provoke a detectable change in students' acceptance of evolution (Demastes-Southerland et al. 1995; Sinatra et al. 2003: Southerland and Sinatra 2003, 2005). Thus it seems that students can achieve gains in understanding of evolution without an accompanying change in their acceptance of theory. Alternatively, students can change their beliefs in evolution without understanding the theory. Here we use the term "belief" deliberately instead of acceptance because acceptance requires some degree of basic understanding, while students can come to believe in a theory without a fundamental understanding (Demastes-Southerland et al. 1995).

To this point, the results of empirical work on acceptance and understanding of evolution suggests that the two are not closely linked. These results are incongruous with the intuitive perspectives of most teachers who have worked in this area. One point that is important to recognize is that most of the current research in this area has focused on:

- Students' acceptance of evolution, measured by instruments such as the Measure of Acceptance of the Theory of Evolution (MATE; Rutledge and Warden 1999).

- Students' knowledge of natural selection (that is, a specific microevolutionary process), as measured through instruments such as the CINS (Anderson et al. 2002) or the UBC (Settlage and Odom 1995).

To understand the implications of research that has focused solely on microevolutionary processes to investigate the intersection between knowledge and acceptance, we need to tread a bit of biological ground.

\section{Microevolution and Macroevolution}

Evolution is a continuous process that unifies aspects of natural selection, environmental changes, adaptation, time, chance, and mutations (Miller 1999). Despite this concise explanation of evolution as a single unified theory, there remains a tendency to divide evolution into processes occurring in the short term (microevolution) and in the long term (macroevolution; Erin 2000). Alters and Alters (2001) define microevolution as "merely changes within the same 'kinds' of organisms" ( $p$ 88) and define macroevolution as "evolution of taxa higher than the level of species" ( $p$ 89). The division between macro and microevolution can be blurred and dynamic, continually adjusting as new evidence is presented and as new organisms or unique features or conditions are discovered (Hendry and Kinnison 2001; Simons 2002).

We recognize the potential for the artificial division of evolution into the relatively contrived categories of microevolution and macroevolution to raise concerns among biologists. However, we contend the division provides a useful context for examining students' understanding and acceptance of the evolutionary process in the short and long term. Therefore, we justify the consideration of these separate categories as pedagogically and psychologically important.

Research describes the differences between some learners' acceptance and understanding of short-term microevolution and long-term macroevolution (Alters and Alters 2001). There is evidence to suggest that students may accept microevolution as a valid scientific explanation (e.g., change in bacteria to become resistant to antibiotics) while they reject macroevolution (e.g., speciation events, that is, new species of organisms arising from an ancestral species; Alters \& Alters; King 2009; Scott 2005). Similarly, some learners may understand the microevolutionary process of natural selection but fail to understand how new species can eventually arise though this process. We argue that if public views short-term evolution (microevolution) as somehow different from their views of long-term evolution (macroevolution), then the somewhat artificial distinction between the two processes may prove to be instrumental and fundamental to our efforts to describe how individuals come to understand and accept evolution.

The bulk of the research examining student understanding of evolution to date has focused on microevolutionary processes (such as natural selection), not macroevolutionary processes and events (such as speciation, fossil evidence; i.e., Anderson et al. 2002: Bishop and Anderson 1990; Nadelson 2009; Sinatra et al. 2003; Southerland and Sinatra 2003, 2005). Because of this methodological limitation, the research conversation in evolution education has taken what has been learned in terms of students' understanding of microevolutionary process and applied it to evolution broadly conceived (including both micro and macroevolution). In short, given the methodological limitation of focusing on perceptions of microevolutionary processes and the tendency of the general public to view micro and macroevolutionary events differently, we argue that much of the past research in this area has overstepped the boundaries of its data.

\section{Research Questions}

Given that much of the previous research suggests that students' acceptance of evolution is not linked to their understanding of microevolutionary processes, we sought to extend this line of work to students' understanding of macroevolution. The questions we used to guide our research were:

1. Is there a relationship between knowledge of macroevolution and acceptance of the theory of evolution? 
2. Is there a relationship between the amount of collegelevel coursework in biology and acceptance of evolutionary theory and knowledge of macroevolution?

3. Can college student acceptance of the theory of evolution and knowledge of macroevolution change over the course of a semester?

We anticipated our participants would respond in a manner indicating a strong relationship between their understanding and acceptance of macroevolution. We hypothesized that college students with greater knowledge of biology, as measured by number of biology courses, would have a higher acceptance and understanding of macroevolution. Furthermore, we predicted that students with extensive coursework in biology would not experience a change in acceptance of evolution as a result of a onesemester course, although we did predict a change in understanding of macroevolution over this time period.

\section{Methodology}

Participants

This research took place in a large urban university in the southeastern USA. The participants were recruited from two courses, an introductory first semester biology course and a capstone undergraduate course in evolutionary biology. Of the 667 participants from the first semester biology course, $61.6 \%$ were female and $38.4 \%$ were male, with an average age of 19.21 years and had taken an average of 0.45 semesters of college level biology courses. The 74 participants from the evolutionary biology course were $66.7 \%$ female and $33.3 \%$ male, with an average age of 22.36 , and had taken an average of 8.87 college level biology courses.

\section{Instruments}

To assess student understanding of macroevolution, we used the recently developed Measure of Understanding of Macroevolution (MUM), the only quantitative measure currently available to assess students' general knowledge of macroevolution. The detailed explanation of the development and process of instrument validation can be found in Nadelson and Southerland (2010). Briefly, the items of this instrument are based on the core concepts of deep time, fossilization, speciation, the nature of science, and classification. The instrument items include a series of questions related to core concepts in reference to scenarios that provide a macroevolution context. The scenarios and questions are based on what is perceived to be foundational knowledge of macroevolution that individuals should have acquired upon completing a standard high school science curriculum. Reliability analysis of the 27-item, forcedresponse instrument revealed a Cronbach's Alpha of 0.87, which indicates the instrument has good reliability.

The Measure of Acceptance of the Theory of Evolution instrument (Rutledge and Warden 1999) was used to determine participants' acceptance of evolutionary theory. This is a 20-item, five-point Likert scale questionnaire with responses ranging from "Strongly Agree" to "Strongly Disagree." Scores range from $20-100$ possible points, with 20 being the lowest level of acceptance and 100 being the highest level of acceptance. The MATE uses items such as, "The theory of evolution is incapable of being scientifically tested." In previous research, the reliability of the instrument was determined to be 0.98 with an item total correlation of $r=0.65$, indicating all items contributed to the total reliability of the instrument. The instrument was developed to determine high-school teacher acceptance of evolutionary theory. The prior reliability values and intended application of the instrument suggest that it was appropriate for use in this study.

\section{Data Collection}

Pre- and post-instruction data were obtained for the evolutionary biology course (allowing us to address research questions 1,2 , and $3 ; N=74$ ). Pre-data were obtained for the introductory biology course (allowing us to address research questions 1 and 2; $N=667$ ). We entered all our data into SPSS, coded it accordingly, and then conducted our analysis.

\section{Analyses and Results}

We began our analysis by calculating the reliability of the MUM and the MATE. For the MUM we achieve a Cronbach's alpha of 0.86 and for the MATE we achieved a Cronbach's alpha of 0.93 . These values indicate a good-toexcellent level of instrument reliability in our study.

Our first research question asked: Is there a relationship between knowledge of macroevolution and acceptance of the theory of evolution? To answer this research question, we combined the data from the introductory biology and evolutionary biology cohorts. Our analysis began by conducting a Pearson's correlational analysis using the scores on the MATE and MUM as our variables. Our results revealed that acceptance of evolution (as measured by the MATE) was correlated to understanding of macroevolution (as measured by the MUM) $r(741)=0.47, p<0.01$. This suggests that as the learners' knowledge of macroevolution increased there was a statistically significant increase in their acceptance of the theory of evolution. 
Our second research question asked: Is there a relationship between the amount of college level course work in biology and acceptance of evolutionary theory and knowledge of macroevolution? To answer this research question we combined the data from the introductory biology and evolutionary biology cohorts. Again we conducted a Pearson's correlational analysis using the number of courses and the scores on the MATE and the MUM. Our analysis revealed that the number of courses was significantly correlated to acceptance $r(741)=0.27 p<0.01$. Our analysis also revealed that the number of courses was significantly related to knowledge of evolution $r(741)=$ $0.35, p<0.01$. This suggests that college level coursework in biology is significantly positively related to students' acceptance of evolution and knowledge of macroevolution.

Our third research question asked: Can college student acceptance of the theory of evolution and knowledge of macroevolution change over the course of a semester? To answer this research question we used the pre- and postcourse MUM and MATE scores of the evolutionary biology students. Given the relatively extensive course work of these students, we did not anticipate significant changes in acceptance (a ceiling effect) but did anticipate a significant change in understanding of macroevolution. The Human Subjects Review Board requirement of participant anonymity complicated the opportunity for a paired samples analysis; therefore an independent samples $t$ test was conducted on course-level pre- and post-scores. The analysis revealed a significant increase in understanding of macroevolution as measured by the MUM, $t(146)=2.77, p<0.01$, which we anticipated. The analysis of acceptance as measured by the MATE was revealed to significantly increase as well $t(146)=$ $3.38, p<0.01$, which we did not anticipate since we assumed that these scores would be rather high and therefore be subject to a ceiling effect. Regardless, these results suggest that in a single course of study students may undergo significant shifts in both their understanding of macroevolution and in acceptance of evolutionary theory. This also provides further evidence indicating that as students' knowledge increases so does their acceptance of evolution.

\section{Discussion}

The relationship and differences between acceptance and understanding of a concept such as evolution has been the subject of continued discussion (Cobern 2004; Smith 1994; Southerland and Sinatra 2003). But it is also apparent that there are philosophical and psychological differences in belief or acceptance and understanding of evolution. Much of the past research in this area has focused on student knowledge of microevolution, but following the work of Catley (2006) and others, we argue that it is necessary to examine the intersection of knowledge, acceptance, and belief in macroevolution as well.

Our findings indicate that acceptance of evolution (broadly conceived, including both micro and macroevolution) and understanding of macroevolution are significantly correlated. This is contrary to the findings of others who have examined this interaction with microevolutionary events. For instance, Sinatra et al. (2003) did not find a relationship between acceptance of evolution and knowledge of microevolution in nonbiology majors.

It is important to note that our results did confirm the detection of the relationship by Southerland and Sinatra (2005), who found a marginally significant relationship between acceptance of evolution and knowledge of microevolution in biology majors. Thus our findings suggest that the relation between acceptance and knowledge varies dependent both on the amount of knowledge a student has about the topic (with students with more knowledge having a close relationship between knowledge and acceptance) and when the construct measured is understanding of macroevolution as opposed to microevolution (as has been the case with past research).

Our results also revealed a significant correlation between amount of coursework in biology with acceptance and understanding of evolution, as was suggested by Southerland and Sinatra (2005). Our findings suggest that educational experience can influence students' knowledge and acceptance of macroevolution. This has important implications for how we prepare scientists and science teachers. There may be a critical threshold of coursework that must be achieved to significantly impact levels of understanding or acceptance of evolution and in particular, macroevolution. We argue that this finding should be further explored to inform college coursework of both biologist and biology teachers.

Our findings indicate a significant change in both understanding of macroevolution and acceptance of evolution during a semester course, even though acceptance of evolution is reported to be a rather stable construct (Rutledge and Warden 1999). This has important implications with regard to evolution education. Our evidence that a single-semester college course can impact acceptance and understanding of evolution suggests that changing the conceptions may be attained through a properly structured curriculum (as has also been reported by Butler (2009)). Further research is needed in this area to determine what aspects of the curriculum may be needed to induce the changes in understanding and to determine if detected changes are long-lasting.

Given the findings of past research in knowledge and belief in microevolution, evolution educators (including the authors) have taken solace in the notion that instruction about evolution may influence a learner's understanding of 
this construct, but not his/her acceptance of it. This has been an important point, as science educators (particularly evolution educators) recognize a change in understanding to be an appropriate goal for science teaching - and have long held that focusing on changing students' acceptance of this construct is "off limits" as a goal for instruction (Smith and Siegel 2004). Thus we thought that as we taught students material that conflicted with their personal belief system, our instruction was unlikely to change their acceptance of material; instead we understood the influence of our teaching to only influence students' understandings of material. Past research suggests this balancing act was a reasonable approach to the teaching of such controversial material (Smith and Siegel 2004; Southerland 2000; Southerland and Sinatra 2003). However, our current findings, given our focus on macroevolution, paint a different landscape. As we expand evolution education to include a greater focus on macroevolutionary events (Cately 2006), our findings suggest that science educators need to attend to the work of Cobern (2004) and consider the interactions of students' out-of-school lives and beliefs with their science learning.

\section{References}

Alexander PA, Dochy FJRC. Conceptions of knowledge and beliefs: a comparison across varying cultural and educational communities. Am Educ Res J. 1995;32:413-42.

Alters BJ, Alters SM. Defending evolution: a guide to the creation/ evolution controversy. Sudbury: Jones \& Bartlett; 2001.

Anderson DL, Fisher KM, Norman GJ. Development and validation of the conceptual inventory of natural selection. J Res Sci Teach. 2002;39:952-78.

Angiullo L, Whitbourne SK, Powers C. The effects of instruction and experience on college students' attitudes toward the elderly. Educ Gerontol. 1996;22:483-495.

Bishop B, Anderson C. Student conceptions of natural selection and its role in evolution. J Res Sci Teach. 1990;27:415-27.

Brem SK, Ranney M, Schindel J. Perceived consequences of evolution: College students perceive negative personal and social impact in evolutionary theory. Sci Educ. 2003;87:181-206.

Butler W. Examining the influence of the nature of science on student learning of biological evolution. Doctoral Dissertation, Florida State University, Tallahassee, Florida; 2009.

Carmel S, Cwikel J, Galinsky D. Changes in knowledge, attitudes, and work preferences following courses in gerontology among medical, nursing, and social work students. Educ Gerontol. 1992;18:329-342.

Catley KM. Darwin's missing link - a novel paradigm for evolution education. Sci Educ. 2006;90(5):767-783.

Cobern B. Apples and oranges: a rejoiner to Smith and Siegel. Sci Educ. 2004;13(6):583-9.

Dagher Z, BouJaoude S. Scientific views and religious beliefs of college students: the case of biological evolution. Sci \& Educ. 1997;6:417-29.

Demastes-Southerland S, Good R, Peebles P. Students' conceptual ecologies and the process of conceptual change in evolution. Sci \& Educ. 1995;79(6):637-66.
Elliot AJ, Dweck CS, editors. Handbook of competence and motivation. New York: Guilford; 2005.

Erickson CK, Wilcox RE, Miller GW, Littlefield JH, Lawson KA. Effectiveness of addiction science presentations to treatment professionals: Using a modified Solomon study design. J Drug Educ. 2003;33:197-216.

Erin DH. Macroevolution is more than repeated rounds of microevolution. Evolut Develop. 2000;2(2):78-84.

Harris MB, Walters LC, Waschull S. Altering attitudes and knowledge about obesity. J Soc Psychol. 1991;131:881-884.

Hendry AP, Kinnison MT. An introduction to microevolution: rate, pattern, process. Genetica. 2001;112-113:1-8.

Jackson DF. Shifting the relationship between personal and professional beliefs and practices with regard to evolution and religion: Three years of feedback from prospective middle school science teachers. A paper presented at the annual meeting of the National Association for Research in Science Teaching, New Orleans, LA; 2000.

King L. A discourse analysis of the adoption of Florida's Science Standards . Unpublished Master's Thesis, Florida State University, Tallahassee, Fl; 2009.

Koumi I, Tsiantis J. Smoking trends in adolescence: Report on a Greek school-based, peer-led intervention aimed at prevention. Health Promot Int. 2001;16:65-72.

Lawson AE, Worsnop WA. Learning about evolution and rejecting a belief in special creation: Effects of reflective reasoning skill, prior knowledge, prior belief and religious commitment. J Res Sci Teach. 1992;29(2):143-166.

Lawson AE, Alkhoury S, Benford R, Clark BR, Falconer KA. What kinds of scientific concepts exist? Concept construction and intellectual development in college biology, J Res Sci Teach. 2000;37:996-1018.

Meadows L, Doster E, Jackson DF. Managing the conflict between evolution and religion. Am Biol Teach. 2000;62(2):102-7.

Miller KR. Finding Darwin's God: a scientist's search for common ground between God and evolution. New York: Cliff Street Books, HarperCollins; 1999.

Nadelson LS. Preservice teacher understanding and vision of how to teach biological evolution. On-line First: Evolution education and Outreach; 2009.

Nadelson LS, Southerland SA (2010). Development and evaluation for a measuring understanding of macroevolutionary concepts: introducing the MUM. J Exp Educ. (in press).

National Academy of Sciences. Teaching about evolution and the nature of science. Washington DC: National Academy; 1998.

Nehm RH, Schonfeld IS. Measuring knowledge of natural selection: A comparison of the CINS, an open-response instrument, and an oral interview. J Res Sci Teach. 2007;45:1131-1160.

Newport F. Republicans, democrats differ on creationism. Retrieved July 14, 2008, from http://www.gallup.com/poll/108226/RepublicansDemocrats-Differ-Creationism.aspx; 2008.

Rutledge ML, Mitchell MA. High school biology teachers' knowledge: Structure, acceptance \& teaching of evolution. Am Biol Teach. 2002;64:21-28.

Rutledge ML, Warden MA. The development and validation of the measure of acceptance of the theory of evolution instrument. Sch Sci Math. 1999;99(1):13-8.

Scharmann LC. Enhancing an understanding of the premises of evolutionary theory: the influence of a diversified instructional strategy. Sch Sci Math. 1990;90(2):91-100.

Scott EC. Evolution vs. creationism: an introduction. Berkeley: University of California; 2005.

Settlage, J., \& Odom, A. L. (1995). Natural selection conceptions assessment: Development of the two-tier test "Understanding Biological Change. Paper presentation at the National Associa- 
tion of Research in Science Teaching annual meeting, April 1995, San Francisco, CA.

Showers DE, Shrigley RL. Effects of knowledge and persuasion on high-school students' attitudes toward nuclear power plants. J Res Sci Teach. 1995;32:29-43.

Simons AM. The continuity of microevolution and macroevolution. J Evol Biol. 2002;15(5):688-701.

Sinatra GM, Pintrich PR. Intentional conceptual change. Mahwah: Lawrence Erlbaum Associates; 2002.

Sinatra GM, Southerland SA, McConaughy F, Demastes J. Intentions and beliefs in students' understanding and acceptance of biological evolution. J Res Sci Teach. 2003;40(5):510-28.

Sinatra GM, Brem SK, Evans EM. Changing minds? Implications of conceptual change for teaching and learning about biological evolution. Evolution: Education and Outreach; 2008.

Smith MU. Counterpoint: belief, understanding, and the teaching of evolution. J Res Sci Teach. 1994;31(5):591-7.

Smith MU, Siegel H. Knowing, believing, and understanding: what goals for science education? Sci Educ. 2004;13(6):553-82.

Smith MU, Siegel H, McInerney JD. Foundational issues in evolution education. Sci \& Educ. 1995;4:23-46.
Southerland SA. Epistemic universalism and the shortcomings of curricular multicultural science education. Sci \& Educ. 2000;9 (3):289-307.

Southerland SA, Sinatra GM. Learning about biological evolution: a special case of intentional conceptual change. In: Sinatra G, Pintrich $\mathrm{P}$, editors. intentional conceptual change. Mahwah: Lawrence Erlbaum Associates; 2003. p. 317-48.

Southerland SA, Sinatra G. The shifting roles of acceptance and dispositions in understanding biological evolution. In: Alsop S, editor. Beyond Cartesian dualism: encountering affect in the teaching and learning of science. The Netherlands: Kluwer Academic; 2005. p. 69-78.

Southerland SA, Sinatra GM, Matthews MR. Belief, knowledge, and science education. Educ Psychol Rev. 2001;13:325-51.

Stanovich KE, West RF. Reasoning independently of prior belief and individual differences in actively open-minded thinking. J Educ Psychol. 1997;89:342-57.

Wood P, Kardash CA. Critical elements in the design and analysis of studies of epistemology. In: Hofer BK, Pintrich PR editors. Personal epistemology. Mahwah, NJ: LEA; 2002. p. 231260. 